\title{
Layer disturbances and the radio-echo free zone in ice sheets
}

\author{
R. Drews ${ }^{1}$, O. Eisen ${ }^{1,2}$, I. Weikusat ${ }^{1}$, S. Kipfstuhl ${ }^{1}$, A. Lambrecht ${ }^{1, *}$, D. Steinhage ${ }^{1}$, F. Wilhelms ${ }^{1}$, and H. Miller ${ }^{1}$ \\ ${ }^{1}$ Alfred-Wegener-Institut für Polar- und Meeresforschung, Bremerhaven, Germany \\ ${ }^{2}$ Institut für Umweltphysik, Heidelberg, Germany \\ *now at: DMT GmbH \& Co. KG, Am Technologiepark 1, 45307 Essen, Germany
}

Received: 20 March 2009 - Published in The Cryosphere Discuss.: 28 April 2009

Revised: 22 July 2009 - Accepted: 28 July 2009 - Published: 25 August 2009

\begin{abstract}
Radio-echo sounding of the Antarctic and Greenlandic ice sheets often reveals a layer in the lowest hundreds of meters above bedrock more or less free of radio echoes, known as the echo-free zone (EFZ). The cause of this feature is unclear, so far lacking direct evidence for its origin. We compare echoes around the EPICA drill site in Dronning Maud Land, Antarctica, with the dielectric properties, crystal orientation fabrics and optical stratigraphy of the EPICADML ice core. We find that echoes disappear in the depth range where the dielectric contrast is blurred, and where the coherency of the layers in the ice core is lost due to disturbances caused by the ice flow. At the drill site, the EFZ onset at $\sim 2100 \mathrm{~m}$ marks a boundary, below which the ice core may have experienced flow induced disturbances on various scales. The onset may indicate changing rheology which needs to be accounted for in the modeling of ice sheet dynamics.
\end{abstract}

\section{Introduction}

For over 40 years radio-echo sounding (RES) has been successfully applied to determine ice thickness and internal structure of large ice bodies. Internal echoes (horizons) are caused by layers contrasting significantly in the dielectric properties of the surrounding ice. The three causes for such changes are: density variations in shallow ice, acid layers and changing crystal orientation fabric (COF) in deeper ice (Fujita et al., 1999). Changes in density and conductivity have isochronous character (Vaughan et al., 2004; Eisen et al.,

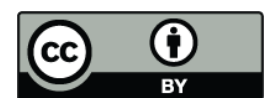

Correspondence to: R. Drews

(reinhard.drews@awi.de)
2004). Changing COF might have isochronous character, but is also influenced by the ice flow (Eisen et al., 2007).

A commonly observed but hitherto unexplained phenomenon is the basal echo free zone (EFZ), a hundreds of meters thick band above the ice bed interface more or less free of radio echoes. The absence of layering was first discussed by Robin et al. (1977) and eventually named as EFZ by Drewry and Meldrum (1978). It is often characterized by an abrupt transition, and an upper onset that varies with depth. It is usually not attributed to the loss of RES sensitivity. Typically it follows the bedrock topography and increases in thickness away from ice domes (Matsuoka et al., 2003). Because direct evidence has been unavailable, it is unclear what triggers the absence of internal reflections within the EFZ, although the EFZ is observed in extensive parts of the Antarctic ice sheet (e.g. Drewry and Meldrum, 1978; Robin and Millar, 1982; Fujita et al., 1999; Siegert and Kwok, 2000; Matsuoka et al., 2003; Wang et al., 2008). Russell-Head and Budd (1979) connected the EFZ observed by Robin et al. (1977) to a layer with low shear stress in the lower third of the ice sheet by Law Dome. Robin and Millar (1982) suggested that the EFZ, observed North of Lake Vostok, is due to a buckling of layers which become increasingly deformed as the bedrock relief starts to influence stress and strain rates towards the bottom. Maccagnan and Duval (1982) proposed that the EFZ onset near the Dome C area represents an isotherm in ice. Fujita et al. (1999) argued for examples at Dome $\mathrm{F}$ that variable shear over an irregular surface causes folding, mixing, and faulting of layers and thus inhibits the return of coherent reflections. Siegert and Kwok (2000) discussed the EFZ observed in subglacial valleys West of Lake Vostok. They described the ice as being potentially stagnant and suggest that recrystallization and recirculation of ice may also play a role.

Published by Copernicus Publications on behalf of the European Geosciences Union. 
If the EFZ is not due to the system sensitivity, Bogorodsky et al. (1985) consider it as a proxy for the reliability of icecore records in paleoclimate resarch which relies on parallel layering for the age-depth conversion. As the EFZ likely indicates a change in flow behavior, the mechanisms are also important for the modeling of ice sheet dynamics and stability (Dowdeswell and Evans, 2004).

In order to check the existing hypotheses we compare airborne RES data around the EPICA drill site at Kohnen station in Dronning Maud Land (DML), Antarctica, with the crystal fabric, optical stratigraphy and dielectrical properties of the $2774 \mathrm{~m}$ long EPICA-DML (EDML) ice core. The geographical setting (Fig. 1) indicates the locations of the RES profiles used in this study (Fig. 2). The ice core is situated on an ice divide in a flank-flow regime. Ice flows towards the Kirwanveggen mountain range, which potentially acts as a barrier for ice flow.

Along with data from dielectric profiling (DEP) and the distribution of $\mathrm{COF}$, we use line-scan images to visualize the integrity of layering. Line-scan images (see Fig. 3) display the stratigraphy of high-scattering zones for light, called cloudy bands (CBs). They correlate with the impurity content of ice (Svensson et al., 2005) and we take them as a proxy for the layering of RES horizons.

So far the comparison of CB layering with RES has not been achieved, because no continuous CB stratigraphy is available for other ice cores from Antarctica. Moreover, only few CBs are seen in the deep ice cores from Byrd, Vostok, and Dome Concordia. The EDML core is the only core from Antarctica with continuous visual stratigraphy and cloudy bands enable a direct comparison with RES data. We find that radio echoes disappear below $\sim 2100 \mathrm{~m}$ at the drill site and that this transition coincides with progressive disturbances in CB-stratigraphy. We discuss possible reasons for the absence of echoes in that zone and implications for the suitability of ice for paleoclimate research and ice-sheet modeling.

\section{Methods and findings}

\subsection{Dielectric profiling and fabric analyzer}

For DEP the ice core is placed between cylindrical electrodes to measure the complex dielectric permittivity from which bulk density and conductivity can be inferred (Wilhelms et al., 1998). The 1-cm electrodes were driven with a $250 \mathrm{kHz}$ signal and shifted along-core with a $0.5 \mathrm{~cm}$ increment. DEP records are corrected for variations in temperature, core diameter, and breaks. The data are scaled (Eisen et al., 2006) to the center frequency of the RES system $(150 \mathrm{MHz})$. In the conductivity profile in Fig. 5a the number and height of peaks decreases towards greater depths. The last dominant peaks rising three times above the background

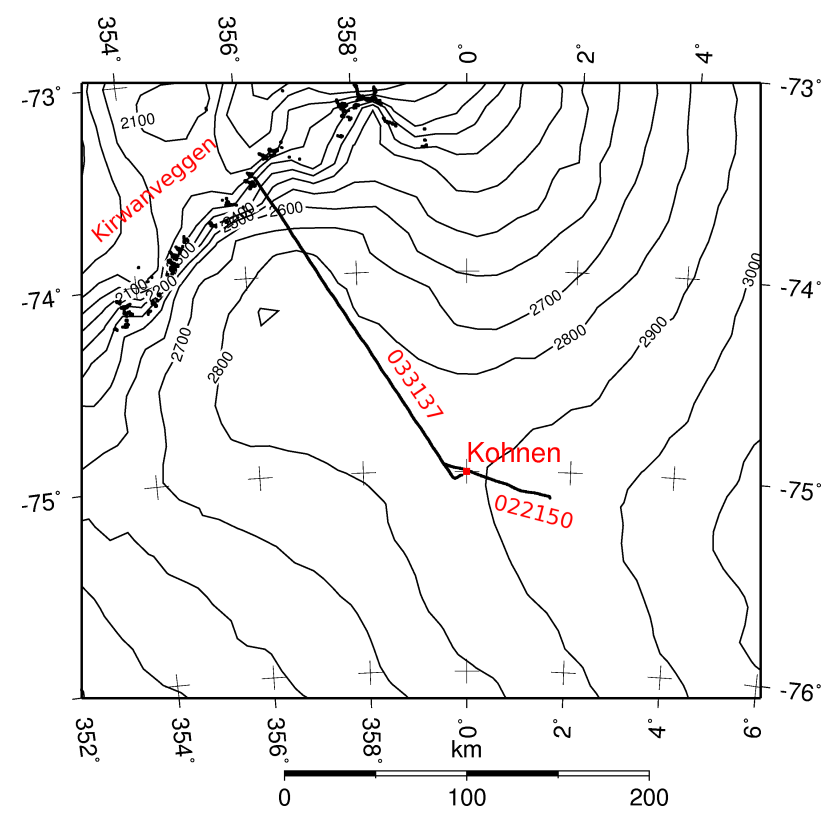

Fig. 1. Location of radar profiles 022150 and 033137 (long black lines) in the vicinity of Kohnen (red dot). Profile 033137 intersects the Kirwanveggen mountain range, which acts as barrier for ice flow. Outcrops of the mountain range are indicated with black dots.

noise occur at $2180 \mathrm{~m}$. Below $2400 \mathrm{~m}$ the typical conductivity peaks are missing.

The fabric data in Fig. 5b are collected from thin sections between crossed polarizers (Wilson et al., 2003). The data are usually displayed in Schmidt diagrams or in terms of three Eigenvalues characterizing an ellipsoid which best approximates the c-axes distribution. Between 2025-2045 m the distribution in COF changes from a vertical girdle type to a single maximum distribution continuing to the bottom. At $\sim 2375 \mathrm{~m}$ the fabric resembles a vertical girdle distribution, but COF data in this depth interval are sparse.

\subsection{Line-scans and ice-core characteristics}

The line-scan camera images 1-m segments of the ice core at a resolution of $0.1 \mathrm{~mm}$ with light (Svensson et al., 2005). While being moved along the core, the camera records light which is scattered by grain boundaries, air-bubbles and microparticles. Transparent zones appear black, and zones with inclusions appear milky (see Fig. 3).

We see progressive disturbances in CB-stratigraphy with depth which correspond to other ice-core characteristics: above $1700 \mathrm{~m}$ the CBs appear straight, smooth, and parallel. They dip slightly due to the inclination of the borehole. Between $\sim 1700-2050 \mathrm{~m}$ the CBs develop mm-scale undulations. From approximately $2050 \mathrm{~m}$ downwards the dip of CBs increases to $10-15^{\circ}$. Most CBs are still parallel, but mm-scaled z-folds start to develop. 
Crystals with diameters larger than $10 \mathrm{~cm}$ are present in the last interglacial (MIS5, 2300-2375 m, age-depth values are based on Ruth et al., 2007) and below $\sim 2600 \mathrm{~m}$. A plot of mean crystal size is published by Weikusat et al. (2009) in Fig. 2a. At the transition from MIS5 to glacial MIS6 (below about $2400 \mathrm{~m}$ ), we see a mixture of dipping and undulating CBs on various scales. In the fine-grained ice of MIS6, the CBs appear parallel, horizontal or inclined up to $30^{\circ}$ alternated with isoclinal z-folds on the $\mathrm{cm}$ - to dm-scale. Below a depth of about $2400 \mathrm{~m}$, CBs increasingly occur with opposite sign of dip within a single core segment of $1 \mathrm{~m}$ length.

We quantified the dip angle of CBs along depth via an automated image analysis. After contrast enhancement and edge detection, the line-scan image of a 1-m segment was binarized. Remaining straight lines with a maximal dip angle of $\pm 45^{\circ}$ from the horizontal (namely CBs) were detected by using a Hough transformation (Hough and Arbor, 1960). In this approach every line connecting two or more pixels is represented as a point in a parameter space (offset and slope), and the strongest lines are identified with a voting procedure (see for example: Burger and Burge, 2008). Between $1500 \mathrm{~m}-2100 \mathrm{~m}, \mathrm{CBs}$ are clearly visbile and approximately 8-15 CBs are detected per image. From $2100 \mathrm{~m}-2370 \mathrm{~m}$, stronger contrast enhancement is necessary and the stratigraphy appears more blurred. In average only 3-7 CBs are detected. Between $2370 \mathrm{~m}$ down to $2500 \mathrm{~m}$, the stratigraphy is more pronounced again. In Fig. 3 the so detected CBs are marked with green lines. It is evident that the procedure does not capture the CBs in their full complexity, but is biased towards thick and non-undulated CBs with a strong contrast. It neglects weaker and undulated CBs. Thus the results should only be regarded as a general trend (for example the mean value of dip angles may vary, depending on the thresholds chosen for the contrast enhancement).

Figure $5 d$ displays the absolute mean dip in a 1-m segment along depth. The mean dip angle varies gradually from 1400-2000 m depth and then exhibits larger variations. Segments with strong mean dip are intersected with segments of smaller mean dip. Below $2100 \mathrm{~m}$ the most of the CBs appear perturbed, but also undisturbed CBs can be found.

\subsection{RES internal structure}

The airborne RES system operates at a frequency of $150 \mathrm{MHz}$ in a toggle mode alternately transmitting a pulse with length of 60 and $600 \mathrm{~ns}$. The theoretical vertical resolution is 5 and $50 \mathrm{~m}$ in ice respectively. Specifics about the radar system are summarized in Table 1, and also discussed by Nixdorf et al. (1999).

Figure 2 displays two profiles in the vicinity of the drill site at Kohnen station. Conversion of two-way traveltime (TWT) to depth is based on synthetic traces (Eisen et al., 2006). Profile 022150 was recorded in 2002 and runs parallel to the ice divide. Profile 033137 was recorded in 2003 and connects Kohnen with the German overwintering station Neumayer.
Table 1. Radar system specification; for wavelength $\lambda$ a permittivity of 3.15 was assumed, $\Delta z$ corresponds to half the pulse length, two antennas with equal transmitting and receiving gain $G$ are used, $P_{t}$ is damped for the short pulse data to maintain a rectangular shape of the ougoing pulse.

\begin{tabular}{llrr}
\hline Parameter & Variable & 60 ns pulse & 600 ns pulse \\
\hline transm. peak power $[\mathrm{dBm}]$ & $\tau$ & 47 & 62 \\
vert. resolution in ice $[\mathrm{m}]$ & $\Delta z$ & 5 & 50 \\
wave length in ice [m] & $\lambda$ & 2 & 2 \\
center frequency [MHz] & - & 150 & 150 \\
antenna type (trans.\& receiv.) & - & short & short \\
& & backfire & backfire \\
antenna gain [dB] & $G$ & 14.2 & 14.2 \\
\hline
\end{tabular}

Detailed internal layering is evident at both pulse lengths in the upper two thirds of the ice column and prominent layers can be traced from one profile to the other. At EDML, the majority of internal reflectors below $\sim 900 \mathrm{~m}$ originate from individual conductivity peaks, with some being an interference signal of closely spaced peaks (Eisen et al., 2006). The last two detected signals in the $60 \mathrm{~ns}$ RES data at EDML correspond to a reflector from changes in COF at $2040 \mathrm{~m}$ (Eisen et al., 2007) and a conductivity peak at $2080 \mathrm{~m}$. The EFZ is observed in both profiles. Figure $4 \mathrm{a}$ and $\mathrm{b}$ display an example from profile 033137 (trace 6297), where the last continuous reflector is found at $1654 \mathrm{~m}$ depth, $690 \mathrm{~m}$ above the icebed interface. The backscattered intensity in the long pulse data drops by $8 \mathrm{~dB}$. At EDML, the EFZ is less pronounced but still evident (see Fig. 4c and d). Below about $2100 \mathrm{~m}$ no continuous internal layering can be found, short and long pulse data fade at similar depth. The last reflector in the long pulse data is about $2 \mathrm{~dB}$ above the noise level. Small signals sometimes appear within the EFZ but these are usually not continuous laterally. An example is visible in Fig. 5e between 2300 and $2400 \mathrm{~m}$ depth. The usually invisible signal becomes only apparent in the differentiated data of the long pulse. The backscattered power is just a few tenths of dB above the noise level. It coincides with the previously mentioned change in $\mathrm{COF}$ at $2375 \mathrm{~m}$, and a section of undisturbed CBs below about $2385 \mathrm{~m}$ depth. Similar reflectors within the EFZ are also observed at other locations (Robin and Millar, 1982).

\subsection{Definition of EFZ-onset and system performance}

The EFZ has been characterized so far by the absence of continuous internal layering above the bedrock, which starts with a sudden drop in backscattered power. The abruptness often negates insufficient radar performance as a primary reason for the EFZ. There is no consensus how strong the drop in backscattered power should be, and since the power drop must be a function of depth, it seems inadequate to tie it to a fixed number. 

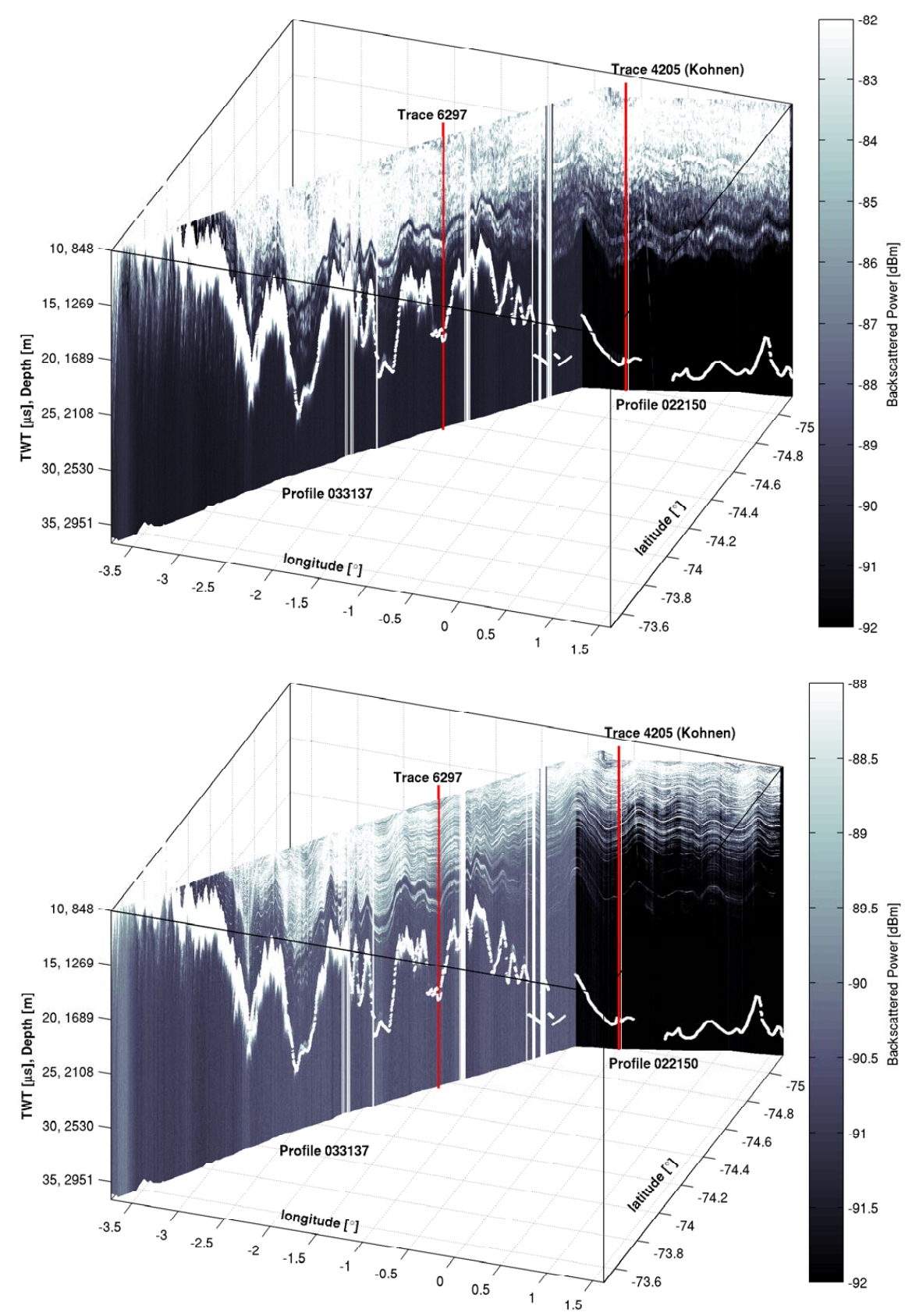

Fig. 2. Radar profiles in the vicinity of Kohnen station recorded with the $60 \mathrm{~ns}$ (bottom) and $600 \mathrm{~ns}$ (top) pulse. Bedrock was picked from differentiated data. The TWT is corrected to the first break of the surface reflection. Units of backscattered power are referenced to $1 \mathrm{~mW}$ $(\mathrm{dBm})$. For better visibility of deeper layers the upper layers have been excluded. Profile 022150 has a length of $40 \mathrm{~km}$ and runs parallel to the ice divide. Ice flow is approximately $1 \mathrm{~m} / \mathrm{a}$. Profile 033137 has a length of $200 \mathrm{~km}$ and intersects the Kirwanveggen mountain range. Although the upper boundary of the EFZ cannot be mapped everywhere, it is clearly visible that it is variable in height and follows the bedrock topography. Traces shown in Fig. 4 are labeled at the top.

We propose two ways how to keep RES sensitivity and other physical mechanisms for the EFZ apart: firstly a comparison of calculated power reflection coefficients (PRCs) from ice-core data with the estimated detection limit of the system, and secondly an in-situ comparison of long and short pulse data.
The PRCs $\left(|R|^{2}\right)$ approximate the scattering cross section in case of an ideal interface. We calculate them from DEP and COF data with the two-layer approximation from Paren (1981). Following Nixdorf et al. (1999), an estimate for the signal to noise ratio $S / N$ can be parameterized with 


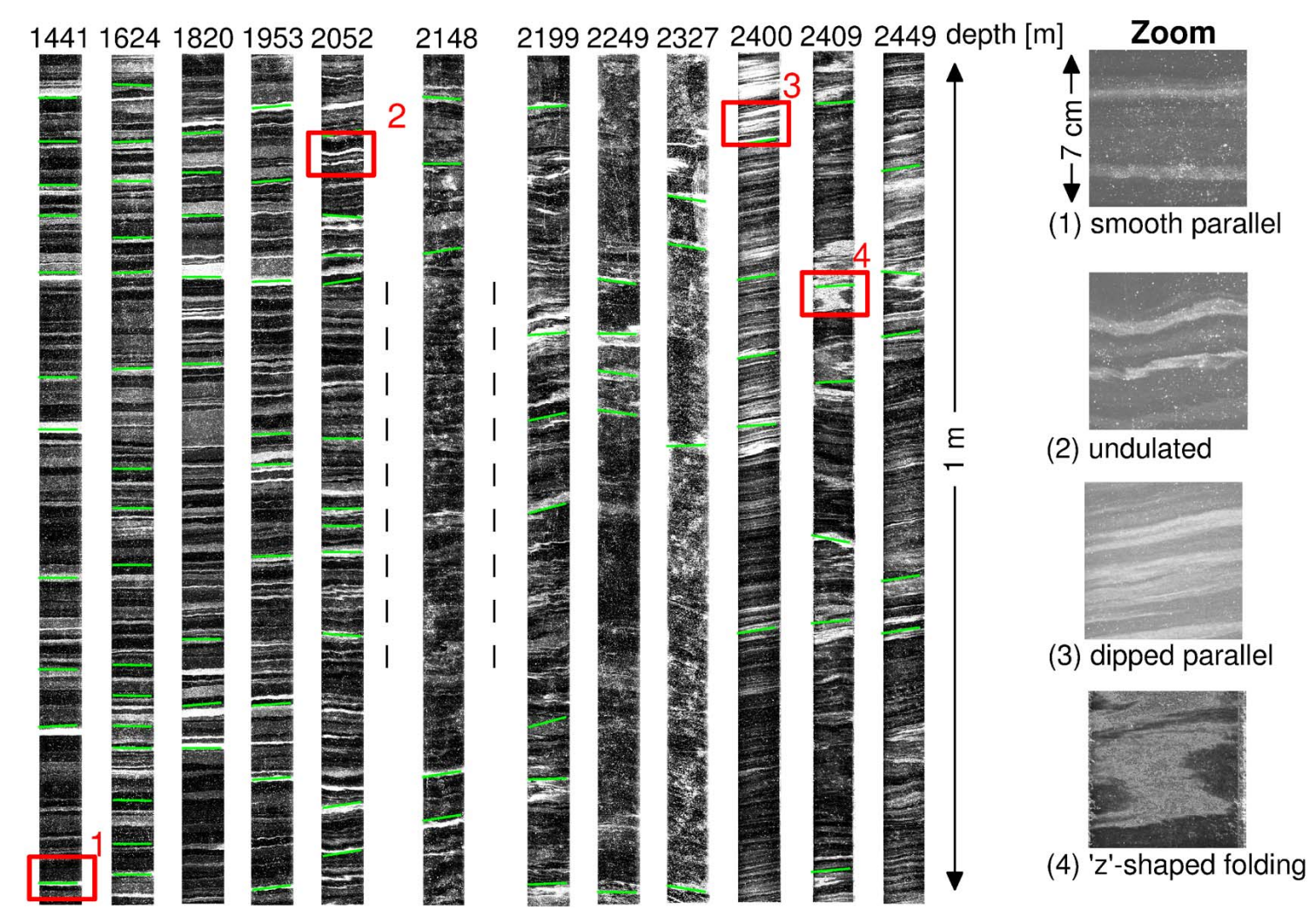

Fig. 3. Line-scan images of the EDML ice core (left) after contrast enhancement. Close-ups of the originial images are visible on the right. Cloudy bands that have been detected with the image analysis are marked in green. The EFZ onset at approximately $2100 \mathrm{~m}$ depth is indicated with dashed lines. Cloudy band stratigraphy appears undisturbed (zoom 1) above EFZ with small-scale undulations (zoom 2) slowly developing. Within the EFZ, layers appear partly dipped parallel (zoom 3) and partly rough as dips point into opposite directions. Dips can be intersected with z-shaped folds (zoom 4).
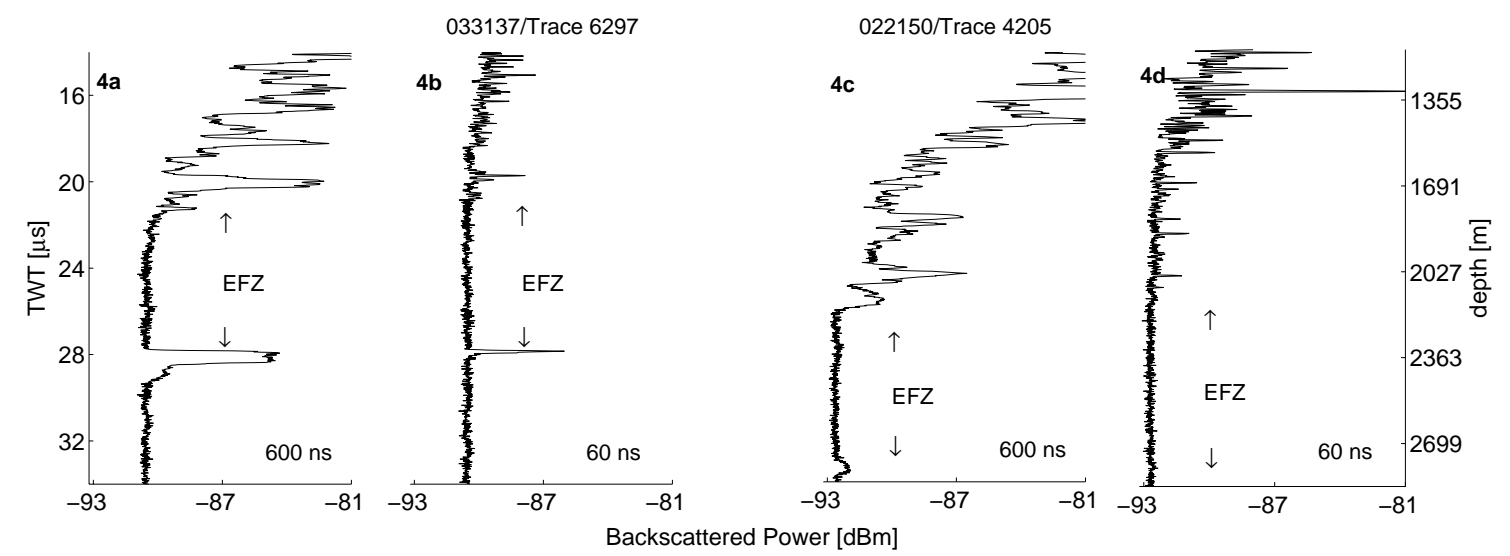

Fig. 4. The EFZ is identified by the simultaneous disappearance of continuous layers in the 60 and 600 ns data, whereby backscattered power in the $600 \mathrm{~ns}$ data drops by several dB. In (a) and (b) trace 6297 (profile 033137) of 600 and $60 \mathrm{~ns}$ data is a typical example for the EFZ. The last continuous signal is visbile at $20.1 \mu \mathrm{s}$ in the $600 \mathrm{~ns}$ and at $19.7 \mu \mathrm{s}(\sim 1654 \mathrm{~m}$ depth) in the $60 \mathrm{~ns}$ pulse. Bedrock is clearly visible in both traces at $27.9 \mu \mathrm{s}(\sim 2344 \mathrm{~m}$ depth). (c) and (d) display trace 4205 (profile 022150) for both pulses at the EPICA drill site. Bedrock is visible in both traces at about $2790 \mathrm{~m}$ depth. Last continuous signals above the bedrock are detected at 25.4 and $25 \mu \mathrm{s}$ TWT $(\sim 2100 \mathrm{~m}$ depth). Because of the larger depth, the signal drop in the $600 \mathrm{~ns}$ data is smaller than in (a). 
$\frac{S}{N}=\frac{P_{t} \tau G^{2} q g_{s t} \lambda^{2}|R|^{2}}{(4 \pi)^{2}[2(H+h)]^{2} L k T}$

where $q$ is the refraction gain, $g_{s t}=200$ is the stacking gain, $H=500 \mathrm{~m}$ is the flight level above surface, $k$ is the Boltzmann constant, $T=400 \mathrm{~K}$ is the noise temperature and $L$ is the attenuation at depth $h$. All other parameters are summarized in Table 1. The loss factor $L=L_{K}^{2}\left(L_{T}\right)^{2} L_{A}$ includes the transmission loss through the surface $\left(L_{T}=1.11\right)$, the cable loss $\left(L_{K}=1.99\right)$, and the two-way dielectric loss $L_{A}$. In analogy to other approaches (MacGregor et al., 2007), we neglect power loss through multiple internal reflections and calculate the total two-way dielectric loss $L_{A}$ as the product of incremental attenuation rates for each measured value of the conductivity. Conductivity has been corrected for temperature with an Arrhenius relation (e.g. MacGregor et al. (2007), Eq. 2). Rearranging Eq. (1) for $|R|^{2}$ with an empirical signal to noise ratio of 1.02 and plotting it along depth results in the two lines displayed in Fig. 5c. These lines mark the estimated detection limit for PRCs for the two different pulses. Compared to the calculated (ideal) PRCs from icecore data, we would expect to detect at least three more layers within the EFZ. However, the estimation of the detection limit does not take into account interference effects and the temperature dependence of the attenuation rates is not fully known. Thus this approach is only a rough estimation.

The radar is usually flown in toggle mode, so that the short pulse can be used to detect internal layering at high vertical resolution and the long pulse for the sounding of bedrock topography. Equation (1) somewhat quantifies this behaviour with the dependency on pulse length $(\tau)$ and emitted peak power $\left(P_{t}\right)$. Pulse length and peak power do not always translate linearly into the signal to noise ratio, as for example $R$ is also dependent on the pulse length (the short pulse layering results from interferences within a smaller vertical interval leading to some differences). However, there is often a direct correspondence between peaks in long and short pulse data - with a better signal to noise ratio in the long pulse data. Therefore we use the deepest layering in the short pulse data as an upper boundary for the detection limit of the long pulse. If layering in long and short pulse data vanish at similar depth, we suspect that at least the absence of layering in long pulse data in a certain interval below that depth is not caused by the system sensitivity. The vertical extent of that interval depends on the drop in backscattered power of the long pulse data. A definition of the EFZ onset in that way is inherently radar dependent, but it bypasses the uncertainties in estimating the detection limit based on the radar equation.

The single traces in Fig. 4a, b demonstrate clearly a correspondence between long and short pulse, together with an $8 \mathrm{~dB}$ drop in backscattered power in the long pulse data. Since it is unlikely that the long pulse is attenuated by $8 \mathrm{~dB}$ within $100 \mathrm{~m}$ below the last reflector, we assume that other mechanisms than mere running out of signal strength must be responsible for the absence of echoes. Single traces at the drill site (Fig. 4c, d) correspond well in long and short pulse data, but the drop in backscattered power in the long pulse data is smaller $(\approx 2 \mathrm{~dB})$. From this example alone, the separation between system performance and other physical mechanisms is not so clear-cut, because the long pulse could be attenuated shortly beneath the disappearance of the short pulse by a slight increase in temperature. However, since the drop in backscattered power must be a function of depth, and because we can trace the EFZ from the previous example (Fig. 4a, b) to the drill site (see also Fig. 2), we conclude that the EFZ is also evident at the drill site. The correspondence of long and short pulse data, and the lateral variation of the EFZ onset around the drill site are indicated in Fig. 5e.

\section{Potential physical mechanisms of the EFZ}

Using the dual-pulse technique described in Sect. 2.4 we identify the EFZ in many places of Fig. 2. An example is shown in Fig. 5e. It is evident that the EFZ's upper onset is variable in height and largely follows the bedrock topography. The onset in Fig. 2 ranges from 1600-2100 m depth, with a $600-700 \mathrm{~m}$ thick gap to the bedrock. Here we discuss potential mechanisms - other than the RES sensitivity for the absence of internal layering around the EPICA-DML drill site. In particular we consider (1) a lack of dielectric contrast, (2) the role of temperature with respect to signal attenuation and the mechanical properties of ice, and (3) the lack of suitable reflecting surfaces due to layer roughness.

The DEP record changes its characteristic below about $2200 \mathrm{~m}$. Conductivity peaks are broader, less distinct and not as frequent. Thus a one dimensional forward model of electromagnetic wave propagation (Eisen et al., 2006) does not predict reflections within the EFZ. The lack of strong conductivity signals can be related to the dipping of layers in the CB stratigraphy. Non-horizontal conductivity signals cause broader and less pronounced peaks, since the DEP device integrates over the entire core diameter $D$ along the horizontal. The magnitude of this effect can be estimated by assuming the conductivity signal $\sigma(z, x)$ to be Gaussian along the vertical $z$ and dipped with slope $m$ along the horizontal $x$. This means $\sigma(z, x)=A \exp \left(-\frac{(z-m x)^{2}}{d^{2}}\right)$, with $A$ determining the peak amplitude and $d$ the peak width. The integration over the core diameter $D$ yields $\sigma(z)=\int_{0}^{D} \sigma(z, x) d x=A \frac{\sqrt{\pi d}}{2 m}\left[\operatorname{ERF}\left(\frac{m}{d} x-\frac{z}{\sqrt{d}}\right)\right]_{0}^{D}$, where ERF stands for the error function. The magnitude of peak broadening is mainly determined by the initial peak width and the dip angle. With an exemplary peak width of $d=2.5 \mathrm{~cm}$ and a dip angle of $15^{\circ}$, the initial peak height decreases by $\sim 15 \%$. However, whether ice dynamics or simple diffusion is the main reasons for the absence of strong conductivity peaks has yet to be determined. As a physical mechanism for the EFZ, a simple lack of dielectric contrast cannot be excluded. 


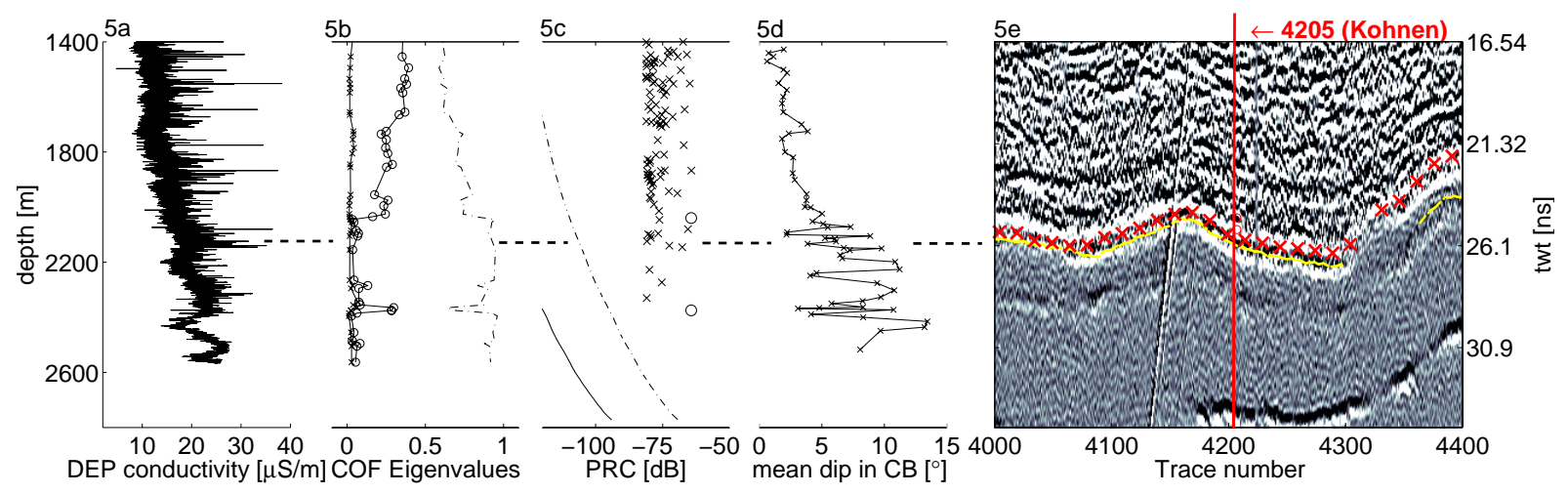

Fig. 5. DEP conductivity profile (a) and COF Eigenvalues (b) from measurements on the EPICA-DML ice core at Kohnen. Power reflection coefficients in (c) are calculated from peaks in DEP-data (x) and change in COF (o) based on the two-layer interface approximation after Paren (1981). The lines indicate the estimated limit of detectable power reflections coefficients for the 60 and $600 \mathrm{~ns}$ pulse dashed and solid, respectively (adapted from Nixdorf et al., 1999). The stratigraphic disturbances observed in the line-scan images are illustrated in (d) as the mean absolute dip of CBs averaged over a 1-m interval along depth. (e) displays differentiated radar data (600 ns) of profile 022150 centered around Kohnen. The last continuous reflector in the $600 \mathrm{~ns}$ data is indicated with the yellow line. The same reflector can be picked in the $60 \mathrm{~ns}$ data (overlaid on the $600 \mathrm{~ns}$ data with red crosses) between traces 4000 and 4300 .

The connection of EFZ onset with an isotherm in ice was previously suggested by Maccagnan and Duval (1982). The temperature distribution in the lower third of an ice sheet is dominated by the geothermal heat flux, but it is also affected by the overburden ice column. If the EFZ onset represents an isotherm, two effects need to be considered: The effect of temperature with respect to attenuation, and the effect of temperature with respect to the mechanical properties of ice. Attenuation usually does not suggest a threshold behaviour. Whereas temperature might play a role in the example of Fig. $4 c-d$, it seems unlikely to be the case for Fig. $4 a-b$ where the dielectric loss would need to be $8 \mathrm{~dB} / 100 \mathrm{~m}$. A change in the mechanical properties of ice around the EFZ onset is supported by the disturbances observed in the linescan data. However, so far there is no evidence that ice develops a threshold behaviour at a certain temperature. We therefore exclude temperature for a driving mechanism for the EFZ onset at EDML.

The correspondence of progressive $\mathrm{CB}$ disturbances and the EFZ onset (see Fig. 5d, e) suggests a physical connection. If the $\mathrm{CB}$ stratigraphy is taken as a proxy for the large scale layering of RES reflectors, it seems that above the EFZ the layering is quasi-parallel, whereas below the EFZ onset the layering is disturbed. A roughening of layer surfaces within the first few Fresnel zones increases the diffuse scattering and reduces the coherent component. A dipping of layers reflects the signal away from the receiver. Studies about scattering on rough interfaces are often based on the Kirchhoff approximation (see for example Ogilvy, 1991), where random and isotropic Gaussian surfaces with a specified rms-roughness and correlation length are used. In our case, we estimate that a rms-roughness of $\sim 0.2 \mathrm{~m}$ results in $\sim 10 \mathrm{~dB}$ loss in the specular component (Peters et al., 2005).
In case layers are dipped, it is possible that the main lobe of the signal is lost, and only sidelobe reflections are received. Both effects cannot be evaluated quantitvely because it is impossible to extrapolate the disturbances seen in the ice core (diameter $10 \mathrm{~cm})$ to the entire Fresnel zone $(\approx 60 \mathrm{~m}$ at $2100 \mathrm{~m}$ depth). If we assume that CB-layers do not intersect (as they are isochrones) we can linearely extrapolate dipped cloudy bands in a single core segment and estimate the layer roughness and correlation length from anticipated intersection points. However, this strongly depends on which CBs are used for extrapolation and also does not boarder the parameters with an upper or lower boundary.

We favour large-scale disturbances in the layering of RES reflectors caused by ice flow as the primary reason for the EFZ at EDML. Deformations on a larger scale are suggested by changing COF at the EFZ onset (see Fig. 5c), and by a change in borehole geometry at $2385 \mathrm{~m}$ depth, when drilling was interrupted for two years during 2004 and 2006 (Faria et al., 2006). The measured borehole closure of $2 \mathrm{~mm} / \mathrm{a}$ indicates an increase in differential flow by an order of magnitude compared to the upper ice column. The climate record is dated to $2417 \mathrm{~m}$ depth. However, Ruth et al. (2007) report increasing difficulties in matching volcanic events with the Dome Concordia record below $1900 \mathrm{~m}$ depth. It is hypothesized that starting at $2050 \mathrm{~m}$ depth, complex flow history and increasing shear stress makes the climate record less reliable until dating is impossible below $2400 \mathrm{~m}$ (S. Faria, personal communication, 2009).

In the vicinity around Dome F an EFZ is also observed. Directly at the dome position the radar signal decreases gradually, but away from the dome in the flank-flow regions the EFZ is evident (S. Fujita, personal communication, 2003, 2008), indicating an ice-dynamical link. The EDML ice 
core is situated in such a flank-flow regime likewise as the GISP2 (Greenland Ice Sheet Project) ice core in Greenland. For GISP2, Jacobel and Hodge (1995) describe the coincident loss of internal layering in analog radar data, at equal depth with dipped stratigraphy in the ice core. Therefore we suggest that for EDML layer roughness (or dip) is the main reason for the loss of internal layering. Not enough data are currently at hand to generalize our results for other places in Greenland and Antarctica.

\section{Conclusions}

It is not finally established whether the primary reason for the EFZ at EDML is related to the dielectric contrast, the temperature, or a larger scale layer roughness. We favour the latter: rough or dipped layers reduce the level of backscatterd power. Possibly other radar systems find the EFZ onset at EDML at a different depth, but a change in backscattered power would still be expected. It is likely that the EFZ is enhanced in flank-flow regimes. The small-scale CB features we describe may belong to disturbances on a larger scale, with overturning and thus age reversal of layers as modeled by Jacobson and Waddington (2005). If this holds true, the onset of the EFZ indicates the beginning of differential flow, with mixing and folding of layers towards greater depth. The interrelation of reflections from changing COF and the EFZ onset, which has also been observed by Matsuoka et al. (2003) and Fujita et al. (1999), has yet to be determined. It is likely that the changing rheology needs to be accounted for in ice-sheet modeling. The EFZ marks the depth within the ice, below which paleoclimate ice-core records may have been influenced by ice flow and need to be interpreted with care.

As the EFZ is detected from above the ice sheet, it is an excellent indicator of disturbances in internal stratigraphy. This is important for future surveys of ice-core sites, particularly for the upcoming search for the oldest ice within the framework of the International Partnerships in Ice Core Sciences (IPICS).

Acknowledgements. This work is a contribution to the European Project for Ice Coring in Antarctica (EPICA), a joint European Science Foundation/European Commission scientific programme, funded by the EU and by national contributions from Belgium, Denmark, France, Germany, Italy, The Netherlands, Norway, Sweden, Switzerland and the United Kingdom. The main logistic support was provided by IPEV and PNRA (at Dome C) and AWI (at Dronning Maud Land). This is EPICA Publication Number 232.

Preparation of this work was supported by the Emmy Noetherprogramme of the Deutsche Forschungsgemeinschaft grant EI $672 / 5$ to O. Eisen and a scholarship of the "Evangelisches Studienwerk e.V. Villigst" to R. Drews.

Edited by: J. L. Bamber

\section{References}

Bogorodsky, V., Bentley, C., and Gudmandsen, P.: Radioglaciology, D. Reidel Publishing Co., 1985.

Burger, W. and Burge, M. J.: Digital Image Processing - An Algorithmic Introduction using Java, Springer, 2008.

Dowdeswell, J. A. and Evans, S.: Investigations of the form and flow of ice sheets and glaciers using radio-echo sounding, Reports on Progress in Physics, 67, 1821-1861, 2004.

Drewry, D. J. and Meldrum, D. T.: Antarctic Airborne Radio Echo Sounding, 1977-78, Polar Record, 19, 267-273, 1978.

Eisen, O., Nixdorf, U., Wilhelms, F., and Miller, H.: Age estimates of isochronous reflection horizons by combining ice core, survey, and synthetic radar data, J. Geophys. Res. - solid earth, 109, B04106, doi:10.1029/2003JB002858, 2004.

Eisen, O., Wilhelms, F., Steinhage, D., and Schwander, J.: Improved method to determine radio-echo sounding reflector depths from ice-core profiles of permittivity and conductivity, J. Glaciol., 52(12), 299-310, doi:10.3189/172756506781828674, 2006.

Eisen, O., Hamann, I., Kipfstuhl, S., Steinhage, D., and Wilhelms, F.: Direct evidence for continuous radar reflector originating from changes in crystal-orientation fabric, The Cryosphere, 1, 1-10, http://www.the-cryosphere.net/1/1/2007/, 2007.

Faria, S. H., Hamann, I., Kipfstuhl, S., and Miller, H.: Is Antarctica like a birthday cake?, www.mis.mpg.de/preprints/ 2006/preprint2006_33.pdf, mPI für Mathematik in den Naturwissenschaften. Leipzig, Communication Preprint No. 33/06, 2006.

Fujita, S., Maeno, H., Uratsuka, S., Furukawa, T., Mae, S., Fujii, Y., and Watanabe, O.: Nature of radio echo layering in the Antarctic ice sheet detected by a two frequency experiment, J. Geophys. Res., 104, 13013-13024, 1999.

Hough, P. V. C. and Arbor, A.: Method and Means for Recognizing Complex Patterns, US Patent 3069654, 1960.

Jacobel, R. W. and Hodge, S. M.: Radar internal layers from the Greenland summit, Geophys. Res. Lett., 22, 587-590, 1995.

Jacobson, H. P. and Waddington, E. D.: Recumbent folding of divide arches in response to unsteady ice-divide migration, J. Glaciol., 51, 201-209, 2005.

Maccagnan, M. and Duval, P.: Electrical behaviour of Antarctic ice and radio echo layers in ice sheets, Ann. Glaciol., 3, 195-198, 1982.

MacGregor, J. A., Winebrenner, D. P., Conway, H., Matsuoka, K., Mayewski, P. A., and Clow, G. D.: Modeling englacial radar attenuation at Siple Dome, West Antarctica, using ice chemistry and temperature data, J. Geophys. Res., 112, F03008, doi:10. 1029/2006JF000717, 2007.

Matsuoka, K., Furukawa, T., Fujita, S., Maeno, H., Uratsuka, S., Naruse, R., and Watanabe, O.: Crystal orientation fabrics within the Antarctic ice sheet revealed by a multipolarization plane and dual-frequency radar survey, Geophys. Res. Solid Earth, 108(B10), 2499, doi:10.1029/2003JB002425, 2003.

Nixdorf, U., Steinhage, D., Meyer, U., Hempel, L., Jenett, M., Wachs, P., and Miller, H.: The newly developed airborne radio-echo sounding system of the AWI as a glaciological tool, Ann. Glaciol., 29, 231-238, doi:10.3189/172756499781821346, 1999.

Ogilvy, J. A.: Theory of Wave Scattering from Random Rough Surfaces, Taylor \& Francis, 1991. 
Paren, J.: Correspondence, J. Glaciol., 27, 203-204, 1981.

Peters, M. E., Blankenship, D. D., and Morse, D. L.: Analysis techniques for coherent airborne radar sounding: Application to West Antarctic ice streams, J. Geophys. Res., 110, B06303, doi: 10.1029/2004JB003222, 2005.

Robin, G. Q. and Millar, D. M.: Flow of ice sheets in the vicinity of subglacial peaks, Ann. Glaciol., 3, 290-294, 1982.

Robin, G. Q., Drewry, D., and Meldrum, D.: International studies of ice sheet and bedrock, Philos. T. Roy. Soc. London, 279, 185196, 1977.

Russell-Head, D. and Budd, W.: Ice-sheet flow properties derived from bore-hole shear measurements combined with icecore studies, J. Glaciol., 27, 117-130, 1979.

Ruth, U., Barnola, J.-M., Beer, J., Bigler, M., Blunier, T., Castellano, E., Fischer, H., Fundel, F., Huybrechts, P., Kaufmann, P., Kipfstuhl, S., Lambrecht, A., Morganti, A., Oerter, H., Parrenin, F., Rybak, O., Severi, M., Udisti, R., Wilhelms, F., and Wolff, E.: "EDML1": a chronology for the EPICA deep ice core from Dronning Maud Land, Antarctica, over the last 150000 years, Clim. Past, 3, 475-484, 2007,

http://www.clim-past.net/3/475/2007/.

Siegert, M. and Kwok, R.: Ice-sheet radar layering and the development of preferred crystal orientation fabrics between Lake Vostok and Ridge B, central East Antarctica, Earth Planet. Sci. Lett., 179, 227-235, 2000.
Svensson, A., Nielsen, S. W., Kipfstuhl, S., Johnsen, S. J., Steffensen, J. P., Bigler, M., Ruth, U., and Rüthlisberger, R.: Visual stratigraphy of the North Greenland Ice Core Project (NorthGRIP) ice core during the last glacial period, J. Geophys. Res., 110, D02108, doi:10.1029/2004JD005134, 2005.

Vaughan, D. G., Anderson, P. S., King, J. C., Mann, G. W., Mobbs, S. D., and Ladkin, R. S.: Imaging of firn isochrones across an Antarctic ice rise and implications for patterns of snow accumulation rate, J. Glaciol., 50(6), 413-418, doi:10.3189/ $172756504781829882,2004$.

Wang., B, Tian, G., Cui, X., and Zhang, X.: The internal COF features in Dome A of Antarctica revealed by multi-polarizationplane RES, Appl. Geophys., 5, 230-237, doi:10.1007/s11770008-0029-z, 2008.

Weikusat, I., Kipfstuhl, S., Faria, S., Azuma, N., and Miyamot, A.: Subgrain boundaries and related microstructural features in EDML (Antarctica) deep ice core, J. Glaciol., 55, 461-472, 2009.

Wilhelms, F., Kipfstuhl, S., Miller, H., Heinloth, K., and Firestone, J.: Precise dielectric profiling of ice cores: A new device with improved guarding and its theory, J. Glaciol., 44, 171-174, 1998.

Wilson, C. J. L., Russell-Head, D., and Sim, H. M.: The application of an automated fabric analyzer system to the textural evolution of folded ice layers in shear zones, Ann. Glaciol., 37(11), 7-17, doi:10.3189/172756403781815401, 2003. 